\title{
Active hunting by deep-diving sperm whales: 3D dive profiles and maneuvers during bursts of speed
}

\author{
Kagari Aoki ${ }^{1, *}$, Masao Amano ${ }^{2}$, Kyoichi Mori ${ }^{3,6}{ }^{\text {, Aya Kourogi }}{ }^{2}$, Tsunemi Kubodera ${ }^{4}$, \\ Nobuyuki Miyazaki ${ }^{5}$ \\ ${ }^{1}$ International Coastal Research Centre, Atmosphere and Ocean Research Institute, The University of Tokyo, Otsuchi, \\ Iwate 028-1102, Japan \\ ${ }^{2}$ Faculty of Fisheries, Nagasaki University, Bunkyo, Nagasaki, 852-8521, Japan \\ ${ }^{3}$ Ogasawara Whale Watching Association, Chichijima, Ogasawara, Tokyo 100-2101, Japan \\ ${ }^{4}$ Department of Zoology, National Science Museum, Shinjuku, Tokyo 169-0073, Japan \\ ${ }^{5}$ Center for International Cooperation, Ocean Research Institute, The University of Tokyo, Nakano, Tokyo 164-8639, Japan \\ ${ }^{6}$ Present address: Department of Animal Sciences, Teikyo University of Science \& Technology, Uenohara, \\ Yamanashi 409-0193, Japan
}

\begin{abstract}
Active hunting pursuit can involve high expenditures of energy and therefore requires appropriately high-energy gains from successful prey capture. Using data loggers deployed on 12 sperm whales off the Ogasawara Islands, we regularly recorded bursts of speed during deep dives. Here, we analyzed speed, acceleration, and 3D data from these maneuvers to describe the whales' hunting behavior. Bursts occurred at depths $>400 \mathrm{~m}$. The median number of bursts was only 1 per dive (range: 0 to 6 per dive), and $33 \%$ of the dives did not include any bursts, suggesting prey capture may not always require bursts. Bursts of speed averaged $3.4 \pm 1.0 \mathrm{~m} \mathrm{~s}^{-1}$ (mean $\pm \mathrm{SD}$; maximum: $\left.8 \mathrm{~m} \mathrm{~s}^{-1}\right)$, more than twice the mean speed observed during dives $(1.5 \pm$ $0.2 \mathrm{~m} \mathrm{~s}^{-1}$ ). Bursts were generally divided into two phases: (1) rapid acceleration with active stroking, and (2) drastic deceleration and changes in body orientation. Tagged whales swam up to $405 \mathrm{~m}$ (mean: $120 \pm 88 \mathrm{~m}$ ) during these two phases. Such behavior suggests chasing of their prey, and should incur high energy expenditure. A large percentage $(20 \pm 14 \%)$ of the drag-related locomotion cost of the dives was spent in bursts. Two major types of bursts were observed: inflectional bursts with turning $(87 \%)$ and linear bursts without turning $(13 \%)$. Our results strongly indicate that sperm whales use an active-pursuit hunting strategy and use the bursts only to catch powerful and nutritious prey (i.e. large and/or muscular) that compensate for the energetic cost of the burst.
\end{abstract}

KEY WORDS: Diving behavior $\cdot$ Hunting tactic $\cdot$ Hunting strategy $\cdot$ Swim speed $\cdot$ Data logger Physeter macrocephalus $\cdot$ Cetacean

\section{INTRODUCTION}

Two main hunting strategies have been reported for both terrestrial and aquatic predators: sit and wait and active pursuit (e.g. Huey \& Bennett 1986). Active pursuit involves higher energy expenditure and requires appropriately high-energy gains from successful prey capture (e.g. Secor 1995). Several studies have reported that aquatic predators increase speed to feed on mobile and larger pelagic fishes (Davis et al. 1999) and decrease speed to feed on small inactive crustaceans (Wilson et al. 2002, 
Watanabe et al. 2004). Energy expenditure and therefore oxygen consumption are predicted to increase as a cubic function of swim speeds (e.g. Kooyman 1989, Otani et al. 2001). Therefore, to maximize foraging efficiency, aquatic predators should match their pursuit speed with prey escape speed that is a function of prey size (Wilson et al. 2002). Thus, both speeds and duration of active pursuit of predators should be indicative of both the prey quality and prey character (e.g. activity and size). In the present study, we focused on pursuit speed to investigate the hunting behavior of the sperm whale Physeter macrocephalus.

The sperm whale is the largest toothed whale and one of the deepest- and longest-diving mammals. Sperm whales routinely dive to depths $>400 \mathrm{~m}$, and such dives are thought to be foraging dives (Watkins et al. 2002). There are a few hypotheses regarding the hunting strategy of sperm whales. Early hypotheses were based on the sit and wait strategy, which is energetically less costly than active pursuit (Beale 1839, Clarke 1970). The more accepted hypothesis is that sperm whales engage in an active search and approach strategy by employing echolocation clicks (e.g. Norris \& Harvey 1972, Møhl et al. 2000, Madsen et al. 2002, Whitehead 2003). Using a tag with tri-axial magnetometers and accelerometers, but without a speed sensor (Dtag; Johnson \& Tyack 2003), Miller et al. (2004b) showed that sperm whales exhibit a rapid decline in the click interval (buzzes) accompanied by increased body movements, suggesting that such behaviors indicate final approach and prey capture. Amano \& Yoshioka (2003) reported that the movements of a tagged sperm whale had events of acceleration of up to about $7.0 \mathrm{~m} \mathrm{~s}^{-1}$. Such events were termed bursts of speed and were suggested to be feeding events. These previous studies support the hypothesis that sperm whales use an active approach strategy rather than a sit and wait strategy when hunting. However, little is known about the range over which sperm whales can adjust their pursuit speed.

The mesopelagic squids found in the stomach contents of sperm whales vary greatly in activity and size, from small chiroteuthids $(<100 \mathrm{~g})$ to large giant squids (Architeuthis sp., up to $400 \mathrm{~kg}$ ) (Clarke 1980, Kawakami 1980). The smaller squids are generally more gelatinous and slow swimming than the larger and more powerful squids preyed on by whales (Clarke et al. 1993). Therefore, large squids probably provide a challenging capture but higher gain in energy compared to the small squids that are the staple food for most sperm whales (Clarke et al. 1993, Whitehead 2003). Although large squids (e.g. Archi- teuthis sp., Ommastreohids, and Taningia danae) account for a small proportion (6\%) of the total number of individuals identified in sperm whales' stomach contents, they provide a substantial proportion of the biomass consumed because of their large size (54\% of total mass; Clarke et al. 1993).

In the present study, we describe bursts of speed using multi-sensor data loggers deployed on 12 sperm whales off the Ogasawara Islands of Japan. To investigate sperm whale hunting behavior, we analyzed detailed 3D dive profiles and maneuvers in relation to swim speeds. Bursts were infrequent, but they accounted for a large percentage of the dragrelated locomotion cost of dives, indicating that sperm whales use the bursts only to catch powerful and nutritious prey.

\section{MATERIALS AND METHODS}

\section{Tag deployment}

Tagging was conducted off the Ogasawara Islands in the western North Pacific Ocean from 2004 to 2008. Groups of female and immature sperm whales are found throughout the year off the Ogasawara Islands (Mori et al. 1995). We approached sperm whales with a fishing boat (length: $20 \mathrm{~m}$ ) and deployed suctioncup attached tags including a data logger using a crossbow or a $6 \mathrm{~m}$ pole. The weight of the whole tag was from 370 to $470 \mathrm{~g}$. The maximum length, width, and thickness of the whole tag was 32,11 , and $5 \mathrm{~cm}$, respectively (for tag details see 'Suction-cup attached tags' and Fig. S1 in the supplement at www.int-res. com/articles/suppl/m444p289_supp.pdf).

Three types of data loggers were used: the UWE2000-PDT (diameter: $21 \mathrm{~mm}$, length: $123 \mathrm{~mm}$, weight: $64 \mathrm{~g}$ in air; Little Leonardo), the W2000PD2GT (diameter: $23 \mathrm{~mm}$, length: $123 \mathrm{~mm}$, weight: $90 \mathrm{~g}$ in air; Little Leonardo) and the W20003MPD3GT (diameter: $30 \mathrm{~mm}$, length: $175 \mathrm{~mm}$, weight: $140 \mathrm{~g}$ in air; Little Leonardo). All data loggers recorded depth, swim speed, and temperature at $1 \mathrm{~s}$ intervals. In addition, the 3MPD3GT recorded the 3D magnetic field at $1 \mathrm{~s}$ intervals and 3D accelerations at $1 / 16 \mathrm{~s}$ intervals (for detecting fluking movements and the body orientation of whales; Fig. 1). The measurement range of the depth sensor of each data logger was from 0 to $2000 \mathrm{~m}$, with a resolution of $0.5 \mathrm{~m}$. We attached the PDT to 2 whales, the PD2GT to 5 whales, and the 3MPD3GT to 5 whales (Table 1; details on the suction-cup attached tags of each type of data logger are in the supplement). 


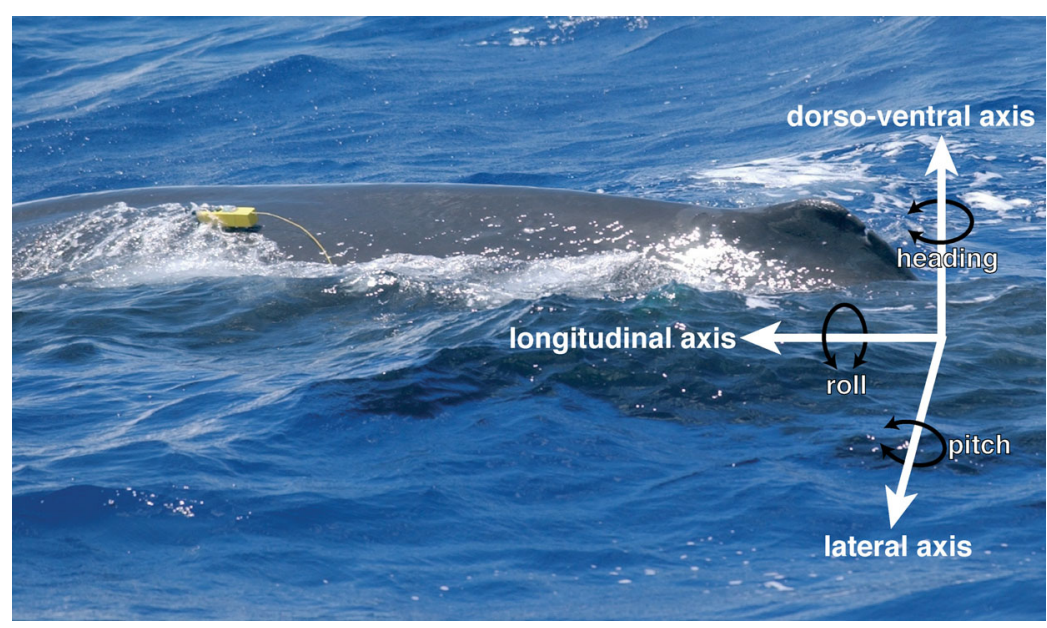

Fig. 1. Physeter macrocephalus. A sperm whale equipped with a suction-cup attached tag including the 3MPD3GT data logger (Type B tag; for details see the supplement at www.int-res.com/articles/suppl/m444p289_supp.pdf). White arrows indicate the tri-axis of the whale. The 3MPD3GT was not always attached parallel to the axes of the tagged whale (for the adjustment of possible off-axes placement, see 'Materials and methods'). The range of body orientation for each axis — pitch: $\pm 90^{\circ}$, roll: $\pm 180^{\circ}$, and heading: 0 to $360^{\circ}$

\section{Data analysis}

The start and end of dives were defined as the time when the whales descended below and ascended above a depth of $4 \mathrm{~m}$, respectively. Although male sperm whales feed near the surface (Teloni et al. 2008), female and immature sperm whales routinely forage in mesopelagic waters (Amano \& Yoshioka 2003, Miller et al. 2004b, Watwood et al. 2006). Off the Ogasawara Islands, female and immature sperm whales also dove to depths $>400 \mathrm{~m}$, and these dives were interpreted to be foraging dives (Aoki et al.

Table 1. Physeter macrocephalus. Summary of tag deployment on 12 sperm whales off the Ogasawara Islands of Japan. For tag type see 'Suction-cup attached tags' in the supplement at www.int-res.com/articles/suppl/m444 p289_supp. pdf. Data logger parameters used were depth, speed and temperature in the PDT and the PD2GT, and depth, speed, temperature, 3D accelerations and 3D magnetism in the 3MPD3GT

\begin{tabular}{|lcccc|}
\hline Whale ID & $\begin{array}{c}\text { Deployment } \\
\text { date }\end{array}$ & $\begin{array}{c}\text { Duration of } \\
\text { attachment }(\mathrm{h})\end{array}$ & $\begin{array}{c}\text { Tag } \\
\text { type }\end{array}$ & $\begin{array}{c}\text { Type of data } \\
\text { loggers }\end{array}$ \\
\hline O4 & 23 Oct 2004 & 2.8 & A & UWE-2000PDT \\
O5a & 9 Sep 2005 & 7.8 & A & UWE-2000PDT \\
O5c & 11 Sep 2005 & 6.9 & B & W2000-PD2GT \\
O5e & 13 Sep 2005 & 8.5 & B & W2000-PD2GT \\
O6b & 11 Sep 2006 & 13.7 & B & W2000-PD2GT \\
O6c & 11 Sep 2006 & 8.0 & B & W2000-PD2GT \\
O6e & 12 Sep 2006 & 9.7 & B & W2000-3MPD3GT \\
O6f & 12 Sep 2006 & 12.0 & B & W2000-PD2GT \\
O8b & 20 Sep 2008 & 9.1 & B & W2000-3MPD3GT \\
O8e & 23 Sep 2008 & 11.1 & B & W2000-3MPD3GT \\
O8f & 23 Sep 2008 & 12.5 & B & W2000-3MPD3GT \\
O8k & 29 Sep 2008 & 14.7 & B & W2000-3MPD3GT \\
\hline
\end{tabular}

2007). According to a histogram of the maximum dive depth, a boundary was observed around $200 \mathrm{~m}$ between shallow and deep dives. We analyzed deep dives with a maximum depth $>200 \mathrm{~m}$. All deep dives were divided into 3 phases: (1) the descent phase (from the start of a dive to the first time at which the depth change rate was negative); (2) the ascent phase (from the last time at which the depth change rate was positive, to the end of the dive); and (3) the bottom phase (the time between the end of the descent phase and the beginning of the ascent phase) (see Aoki et al. 2007 for details). Dive depth was defined as the maximum depth of the dive. Post-dive surface duration was defined as the time between the end of the dive and the start of the next dive.

Speed through the water was measured using an external propeller on the data logger. The rotation rate (revolutions $\mathrm{s}^{-1}$ ) of the propeller was converted to swim speed $\left(\mathrm{m} \mathrm{s}^{-1}\right)$ using a calibration line for each whale. We used 2 different methods to obtain calibration lines, with the method used dependent upon the type of data logger used. A linear regression of revolutions per second against the rate of vertical depth change $\left(\mathrm{m} \mathrm{s}^{-1}\right)$ was used to estimate a calibration line for whales tagged with the PDT or PD2GT data loggers (modified from Blackwell et al. 1999, see Aoki et al. 2007 for details; Fig. S2 in the supplement). We regressed third, fifth, and tenth percentile points of propeller rotation data to corresponding vertical depth change rates in each whale's data and used the line with the highest regression coefficient value for each whale. Another method was employed for each whale tagged with the 3MPD3GT after analyzing acceleration data. A calibration line was obtained from a linear regression of revolutions per second against swim speed $\left(\mathrm{m} \mathrm{s}^{-1}\right)$, which was calculated from the rate of vertical depth change divided by the sine of the pitch when the sine of the adjusted pitch (see below) was $>0.9$ (see Sato et al. 2003 for details and Fig. S3 in the supplement). Both methods yielded relatively high regression coefficients (range: 0.801 to $0.998 ; \mathrm{n}=12$ whales). Resolutions of swim speed, 
which correspond to 1 rotation of the propeller, ranged from 0.014 to $0.052 \mathrm{~m} \mathrm{~s}^{-1}$ ( $\mathrm{n}=12$ whales). The swim speeds, directly derived from the rotation rate, were in the range of 0.1 to $3.8 \mathrm{~m} \mathrm{~s}^{-1}$ ( $\mathrm{n}=12$ whales).

Accelerations in the tri-axis (longitudinal, lateral, and dorso-ventral axes) measured using the 3MPD3GT data logger can be broken into components related to the body orientation of the animal with respect to gravity (gravity-based components) and propulsive activities imposed by fluke thrust (dynamic components, which is also called specific or platform acceleration) (Sato et al. 2003, Watanabe et al. 2006). Lower-frequency gravity-based accelerations of all axes were extracted from raw acceleration data using the low-pass filter of the software IFDL within IGOR Pro (WaveMetrics). A frequency boundary for the filter was determined for each whale (range: 0.0933 to $0.125 \mathrm{~Hz}$ ) by calculating the power spectral density of the raw acceleration data (see Watanabe et al. 2006 for details). For this calculation, the bottom phases of the dives were excluded because the body rotations recorded in the bottom phase seemed to occur at rates similar to those of stroking action. We therefore note that it was impossible to separate these components perfectly in the bottom phases. Lower-frequency gravity-based acceleration of the longitudinal axis was used to calculate the pitch angle of the data logger (Sato et al. 2003). The roll angle of the data logger was calculated from the gravity-based components of dorsoventral and lateral accelerations based on Johnson \& Tyack (2003) (see also Shiomi et al. 2010 for details).

Since the data logger was not always attached exactly parallel to the axes of the whale, it was necessary to correct attachment angle. Corrected values, calculated to adjust pitch, were used to compensate for possible off-axis placement on the body by using the cumulative value method for each dive per whale (see Sato et al. 2003 for details). Absolute differences in the corrected values between dives averaged $2.8 \pm 2.5^{\circ}(\mathrm{n}=65$ dives$)$, indicating good tag stability on the animal. Corrected values, calculated to adjust for roll, were obtained to compensate for possible off-axis placement on the body based on 2 criteria for each dive per whale: (1) the roll of the whale should equal zero when the whale was resting at the surface between deep dives and (2) the corrections should match the visually inspected orientation of the tag on the whale (Miller et al. 2004a). Absolute differences of the corrected values between dives averaged $4.2 \pm 6.4^{\circ}(\mathrm{n}=65$ dives). Magnetism values change depending on the angles between the geomagnetic vector and each axis of the data logger. Therefore, the heading of the data logger (i.e. heading of the whale) was calculated from adjusted pitch and roll and triaxis magnetism (see Johnson \& Tyack 2003 for details) using a macro, programmed by T. Narazaki (Narazaki \& Shiomi 2010), for the program IGOR Pro (WaveMetrics). We assumed that the heading of the data logger did not differ dramatically from that of the tagged whales (see 'Suction-cup attached tags' in the supplement for details). The tags were not initially deployed parallel to the body axes of the animals; however, they shifted to an almost parallel position after several minutes, suggesting that tags became nearly parallel to the body axes of the animals owing to the water flow (see Sakai et al. 2011 for details). However, we were unable to check the tag position during each surfacing event for all the tagged whales. Therefore, the heading of the data-logger was probably not exactly parallel to body axes for all the whales. This might have caused estimates of speed to be reduced or increased to some extent (see 'Data analysis' in the supplement for details). However, we think that these effects did not remarkably change our main results.

Horizontal swim speed of each whale was calculated by cosine (pitch of the whale) $\times$ swim speed. Thereafter, the 3D dive profiles were estimated by depth, heading, and horizontal swim speed of the whale (i.e. dead reckoning; Wilson et al. 1991). To identify strokes, the higher frequency dynamic acceleration of dorso-ventral axis was obtained by subtracting low-frequency components from the raw acceleration data. The peaks and troughs of the signal with absolute amplitudes greater than a specified threshold were considered to represent individual strokes (Sato et al. 2003). To select the threshold, we made a histogram of absolute amplitudes from all peaks and troughs for each whale. This analysis showed a clear boundary between small noises and strokes. We defined the boundary as the threshold for each whale (range: 0.25 to $1.67 \mathrm{~m} \mathrm{~s}^{-2}$ ).

A burst (Fig. 2) was defined based on the following 2 conditions: (1) forward acceleration was $>0.15 \mathrm{~m} \mathrm{~s}^{-2}$ calculated from swim speed at $5 \mathrm{~s}$ intervals and (2) swim speed reached more than the mean $+1.5 \mathrm{SD}$ of the bottom phase of each dive (see also Fig. S4 in the supplement). The start of a burst was defined as the time when swim speed began to increase. The end of a burst was defined as the time when the tagged whales began to swim constantly again, or the swim speed decreased to less than the mean speed of the bottom phase. Bursts were expressed as events that included relatively high speed with strong forward accelerations (Fig. S4 in the supplement). We therefore focused on the tails of swim speed histograms 
a
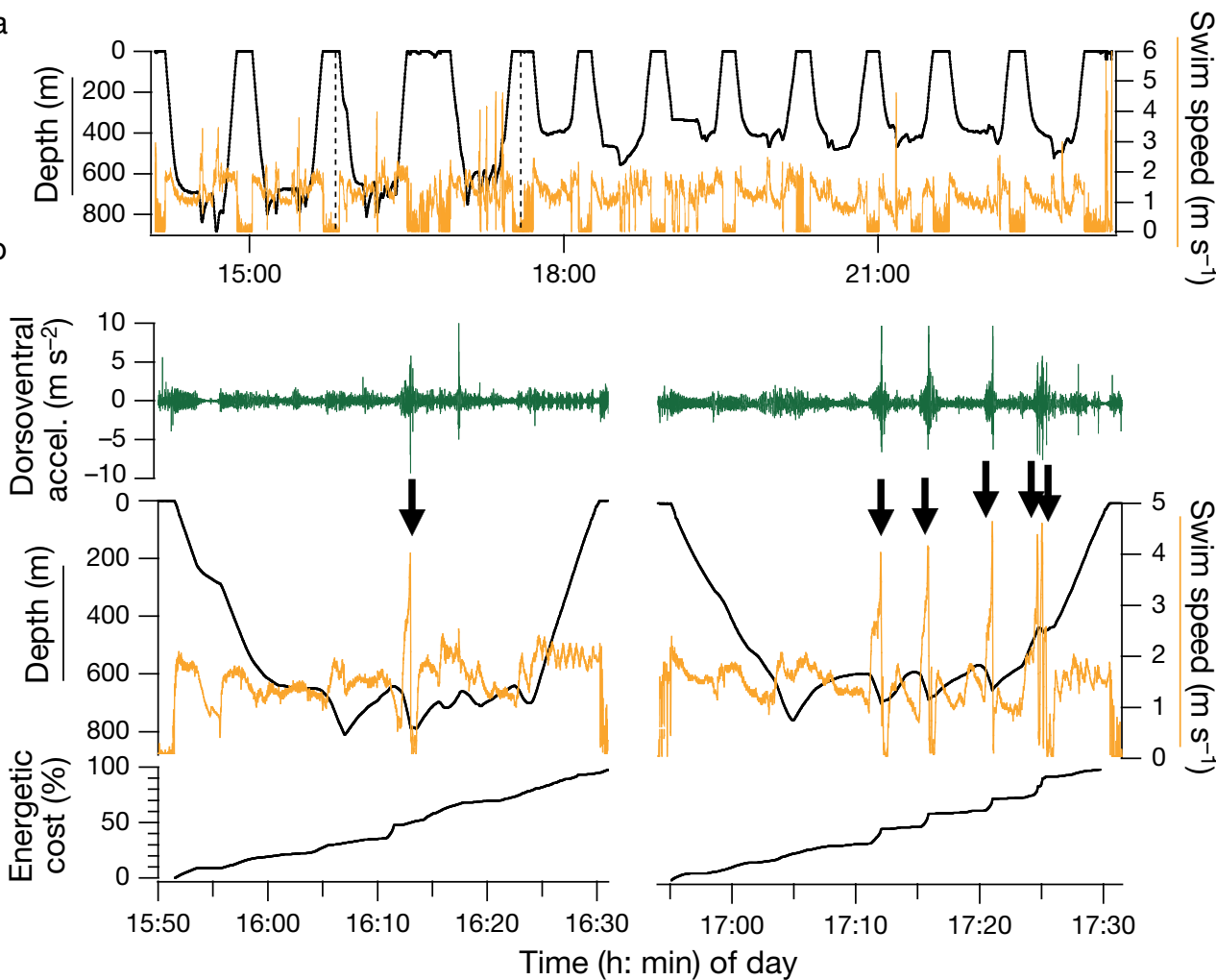

Fig. 2. Physeter macrocephalus. Depth (black line), swim speed (orange line), and dorso-ventral accelerations (accel.) of a sperm whale (ID O8b) off the Ogasawara Islands of Japan. (b) Enlarged profile of the graph between the dashed lines in Panel (a). Black arrows highlight bursts of speed. Cumulative energetic cost was approximated by integrating the cube of swim speed of each dive

during deep dives as bursts (see Fig. 3a). To investigate maneuvers of the whales, changes in body orientation (i.e. pitch, roll, and heading) $\left({ }^{\circ} \mathrm{s}^{-1}\right)$ were calculated at $1 \mathrm{~s}$ intervals. High rates of change in body orientation (>mean + SD during bursts which corresponded to means $+10 \mathrm{SD}$ during deep dives: pitch: $7^{\circ} \mathrm{s}^{-1}$, roll: $15^{\circ} \mathrm{s}^{-1}$, heading: $21^{\circ} \mathrm{s}^{-1}$ ) were picked up as rapid changes in body orientation during bursts. We investigated temporal occurrence of rapid changes in body orientation, changes in depths, and the presence of turns during bursts (see 'Data analysis' in the supplement for details).

The lack of data on the metabolic rate of sperm whales prevents precise calculation of the locomotion cost of bursts. The mechanistic model used to describe locomotion cost is based on the hydrodynamic drag experienced by the animal (Hind \& Gurney 1997). The drag force scales with the square of swim speed, $U$ (Vogel 1981). The power required to overcome this drag force can be approximately scaled with $U^{3}$ (Hind \& Gurney 1997), if we assume that the propeller efficiency and drag coefficient are constant over a range of swim speeds. Therefore, the ratio of the cost of bursts to the whole dive locomotion cost $\left(C L_{\mathrm{b} / \mathrm{d}}\right)$ can be estimated by:

$$
C L_{b / d} \approx\left(\int_{t b} U^{3} d t\right)\left(\int_{t d} U^{3} d t\right)^{-1}
$$

where $t b$ is the duration of bursts and $t d$ is the duration of the whole dive (Aguilar Soto et al. 2008).

All statistical analyses were performed using the $\mathrm{R}$ 2.6.2 package (The R Foundation for Statistical Computing, Vienna) (see the supplement for details of statistical analyses). Values for statistical significance were set at $\mathrm{p}<0.05$. We report means $\pm \mathrm{SD}$.

\section{RESULTS}

A total of $116.8 \mathrm{~h}$ of data, including 126 complete dives (maximum depth: $>200 \mathrm{~m}$ ), were obtained from 12 tagged sperm whales Physeter macrocephalus off the Ogasawara Islands. All tagged whales were determined to be mature females or immature individuals on the basis of their size and external appearance (estimated body length by sight: 6 to $10 \mathrm{~m}$ ). Maximum dive depths and duration were $1422 \mathrm{~m}$ and $53 \mathrm{~min}$, respectively (mean dive depth: $695 \pm$ $247 \mathrm{~m}$, mean dive duration: $33 \pm 6 \mathrm{~min} ; \mathrm{n}=126$ dives). The whales swam continuously during deep dives (Fig. 2). The mean swim speed during a whole dive was $1.5 \pm 0.2 \mathrm{~m} \mathrm{~s}^{-1}(\mathrm{n}=126$ dives; Table 2, Fig. 3a). The mean speed of each phase was $1.4 \pm 0.3 \mathrm{~m} \mathrm{~s}^{-1}$ during descent, $1.6 \pm 0.3 \mathrm{~m} \mathrm{~s}^{-1}$ at the bottom of the dive, and $1.6 \pm 0.3 \mathrm{~m} \mathrm{~s}^{-1}$ during ascent ( $\mathrm{n}=126$ dives) The tagged whales spent most of their time in deep 
a

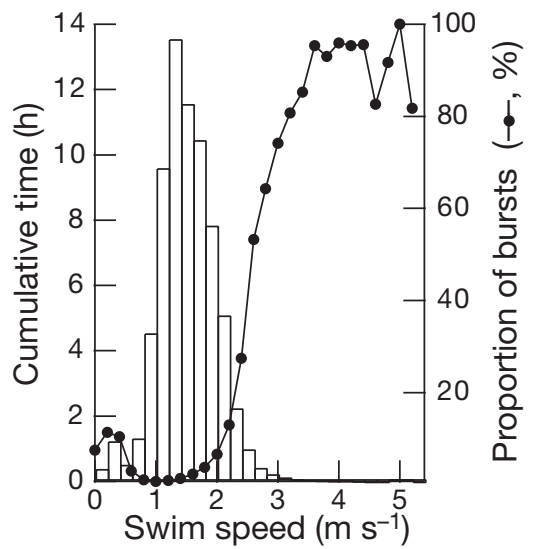

b

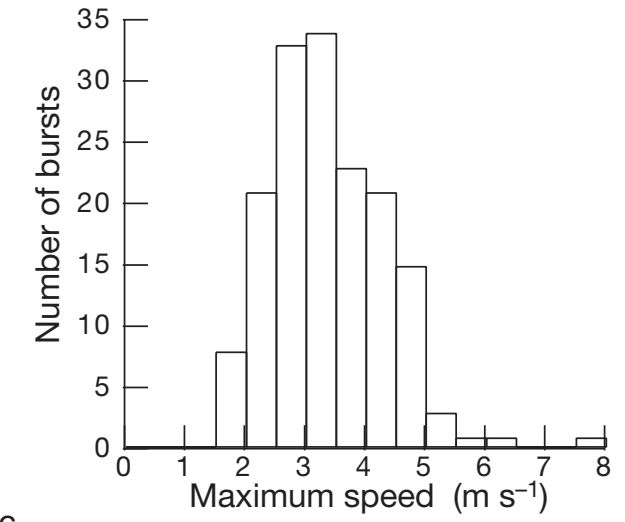

C

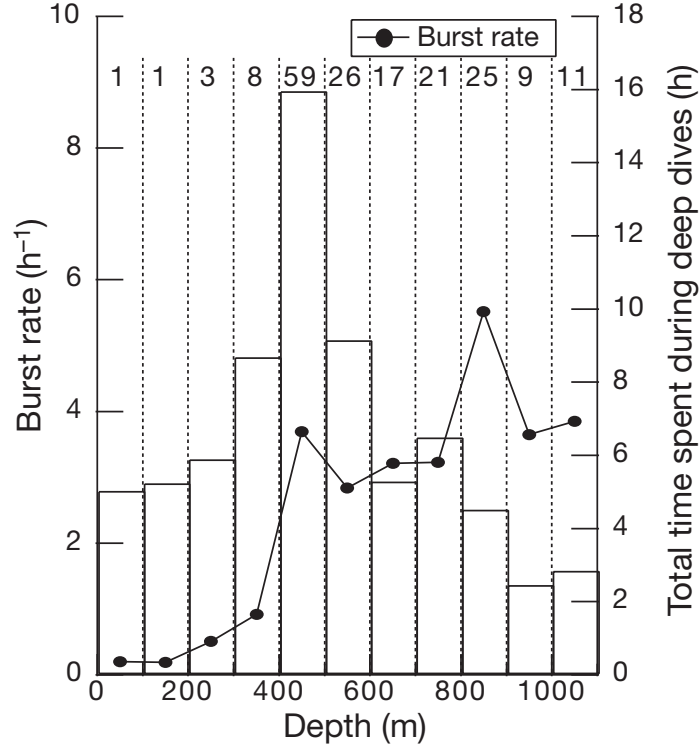

Fig. 3. Physeter macrocephalus. (a) Distribution of swim speed during deep dives and the proportion of bursts at each swim speed. (b) Histogram of the maximum speed of each burst. (c) Number of bursts per hour and the total time spent at each depth. Data of all 12 sperm whales off the Ogasawara Islands were used. In (a), data were pooled for speeds $>5.2 \mathrm{~m} \mathrm{~s}^{-1}$ because of small samples (number of points at each speed: $\leq 10)$. In (c), the number at the top of each bar shows the number of bursts for each depth bin. Data were pooled for depths $>1000 \mathrm{~m}$ because of small samples (number of bursts: $\leq 5$, total time spent at each depth: $\leq 2 \mathrm{~h}$ ) dives that exceeded a maximum depth of $200 \mathrm{~m}$ $(81.4 \pm 24.5 \% ; \mathrm{n}=12$ whales $)$. All whales tagged with the 3MPD3GT glided more during ascent than in descent (gliding rate-descent: $29.1 \pm 5.0 \%$, ascent: $57.1 \pm 19.8 \% ; \mathrm{n}=5$ whales $)$.

Bursts of speed (Fig. 2) were observed from all tagged whales. A total of 181 bursts were recorded (median: 1 per dive, range: 0 to 6 per dive; $\mathrm{n}=126$ dives; Table 2). However, $33 \%$ of dives did not include any bursts, and the remaining $67 \%$ of dives included 1 burst at least. The mean and maximum durations of the bursts were $58 \pm 37 \mathrm{~s}$ and $176 \mathrm{~s}$, respectively ( $\mathrm{n}=181$ bursts). During a burst, maximum swim speed was generally between 2 and $5 \mathrm{~m} \mathrm{~s}^{-1}\left(3.4 \pm 1.0 \mathrm{~m} \mathrm{~s}^{-1} ; \mathrm{n}=161\right.$ bursts $)$, but reached $8.0 \mathrm{~m} \mathrm{~s}^{-1}$ (Fig. 3b). The total swimming distance of the bursts had a range of 8 to $405 \mathrm{~m}(120 \pm 88 \mathrm{~m} ; \mathrm{n}=161$ bursts). The ratio of the cost of bursts to the whole dive locomotion cost averaged $20 \pm 14 \%$ (range: 1 to $70 \%)$ at dives where at least 1 burst was observed ( $\mathrm{n}=73$ dives). We note that 12 dives including bursts were not used for this calculation (see supplement for details). Burst rates were significantly higher during the bottom phase $\left(4.2\right.$ bursts $\left.^{-1}\right)$ than during descent $\left(1.2\right.$ bursts $\left.\mathrm{h}^{-1}\right)$ or ascent phases $\left(0.7\right.$ bursts $\left.\mathrm{h}^{-1}\right)$ (Kruskal-Wallis test, $\chi_{2}^{2}=15.1, \mathrm{p}<0.001$ ). More than $90 \%$ of bursts occurred at depths $>400 \mathrm{~m}$. Bursts were most frequent between 800 and 900 m (Fig. 3c). In contrast, the tagged whales most frequently stayed between 400 and $500 \mathrm{~m}$, and time spend at depths beyond $400 \mathrm{~m}$ decreased with increasing depth (Fig. 3c).

\section{Maneuvers and 3D dive profiles during bursts}

A total of $69.5 \mathrm{~h}$ of data, including 106 bursts, were obtained from 5 whales tagged with the 3MPD3GT. Tagged whales swam steadily before the start of $61 \%$ of bursts, but gliding was recorded prior to $39 \%$ of bursts (duration of gliding: $57 \pm 42 \mathrm{~s}$, maximum: $177 \mathrm{~s} ; \mathrm{n}=41$ ). Change in body orientation was slow during gliding, with no active stroking (mean change rate: pitch: $1 \pm 1^{\circ} \mathrm{s}^{-1}$, roll: $2 \pm 1^{\circ} \mathrm{s}^{-1}$, heading: $2 \pm 1^{\circ}$ $\mathrm{s}^{-1} ; \mathrm{n}=41$ ), and the mean swim speed was $1.2 \pm 0.4 \mathrm{~m}$ $\mathrm{s}^{-1}(\mathrm{n}=41)$.

During bursts, whales exhibited rapid acceleration and drastic deceleration of swim speed (maximum acceleration during each burst: $0.28 \pm 0.11 \mathrm{~m} \mathrm{~s}^{-2}$, maximum deceleration during each burst: $-0.55 \pm$ $0.36 \mathrm{~m} \mathrm{~s}^{-2} ; \mathrm{n}=106$ ). To investigate whether deceleration during bursts was passive or actively generated by the animal, we compared deceleration rates dur- 
Table 2. Physeter macrocephalus. Summary of dive statistics on 12 sperm whales off the Ogasawara Islands of Japan. Means $\pm \mathrm{SD}$ are shown. Swim speed was averaged during a whole dive. Median number of bursts in parentheses

\begin{tabular}{|lccccccc|}
\hline Whale ID & $\begin{array}{c}\text { No. of } \\
\text { deep dives }\end{array}$ & $\begin{array}{c}\text { Dive depth } \\
(\mathrm{m})\end{array}$ & $\begin{array}{c}\text { Dive duration } \\
(\mathrm{min})\end{array}$ & $\begin{array}{c}\text { Bottom duration } \\
(\mathrm{min})\end{array}$ & $\begin{array}{c}\text { Post-dive surface } \\
\text { duration }(\mathrm{min})\end{array}$ & $\begin{array}{c}\text { Swim speed } \\
\left(\mathrm{m} \mathrm{s}^{-1}\right)\end{array}$ & $\begin{array}{c}\text { No. of bursts } \\
(\text { dive }\end{array}$ \\
\hline O4 & 3 & $810 \pm 256$ & $35.2 \pm 2.9$ & $17.6 \pm 2.4$ & $12.5 \pm 9.5$ & $1.9 \pm 0.2$ & $3.7 \pm 2.1(3)$ \\
O5a & 10 & $736 \pm 206$ & $30.8 \pm 5.6$ & $14.5 \pm 5.6$ & $11.7 \pm 4.0$ & $1.8 \pm 0.3$ & $1.0 \pm 0.8(1)$ \\
O5c & 5 & $999 \pm 198$ & $37.1 \pm 2.2$ & $18.1 \pm 4.5$ & $15.7 \pm 8.6$ & $1.7 \pm 0.2$ & $1.0 \pm 0.7(1)$ \\
O5e & 6 & $922 \pm 322$ & $32.6 \pm 8.7$ & $14.5 \pm 6.0$ & $10.6 \pm 1.7$ & $2.0 \pm 0.3$ & $0.2 \pm 0.4(0)$ \\
O6b & 16 & $842 \pm 301$ & $37.7 \pm 9.3$ & $19.9 \pm 7.3$ & $11.7 \pm 5.2$ & $1.8 \pm 0.2$ & $2.1 \pm 1.6(2)$ \\
O6c & 10 & $627 \pm 132$ & $36.6 \pm 2.4$ & $20.5 \pm 2.8$ & $8.6 \pm 1.8$ & $1.6 \pm 0.1$ & $0.8 \pm 0.6(1)$ \\
O6e & 11 & $801 \pm 275$ & $35.1 \pm 3.3$ & $17.5 \pm 3.9$ & $11.6 \pm 5.0$ & $1.7 \pm 0.2$ & $3.2 \pm 1.3(3)$ \\
O6f & 4 & $498 \pm 5$ & $33.6 \pm 3.8$ & $12.9 \pm 8.2$ & $9.6 \pm 2.4$ & $1.6 \pm 0.5$ & $1.8 \pm 1.3(2)$ \\
O8b & 12 & $587 \pm 172$ & $34.6 \pm 4.2$ & $20.2 \pm 3.1$ & $10.1 \pm 5.1$ & $1.6 \pm 0.2$ & $1.1 \pm 1.4(1)$ \\
O8e & 16 & $582 \pm 101$ & $29.8 \pm 3.0$ & $14.7 \pm 4.4$ & $10.0 \pm 6.1$ & $1.6 \pm 0.2$ & $1.1 \pm 1.4(0.5)$ \\
O8f & 16 & $689 \pm 275$ & $29.3 \pm 4.6$ & $14.5 \pm 4.1$ & $9.7 \pm 3.1$ & $1.6 \pm 0.3$ & $1.6 \pm 1.5(1)$ \\
O8k & 17 & $548 \pm 149$ & $30.9 \pm 3.1$ & $14.3 \pm 5.4$ & $10.2 \pm 6.3$ & $1.3 \pm 0.3$ & $0.9 \pm 1.3(1)$ \\
Mean \pm SD & & $694 \pm 247$ & $33.1 \pm 5.7$ & $16.6 \pm 5.5$ & $10.7 \pm 5.0$ & $1.5 \pm 0.2$ & $1.5 \pm 1.5(1)$ \\
Max. & & 1422 & 53.2 & 32.3 & 32.4 & 2.2 & 6 \\
Min. & & 270 & 16.0 & 1.5 & 6.0 & 0.9 \\
\hline
\end{tabular}

ing bursts with those recorded during glides. We extracted deceleration rates during horizontal swimming for both bursts and glides because the buoyancy of the animals causes acceleration/deceleration during descent and ascent glides (Miller et al. 2004a, Watanabe et al. 2006). Additionally, we used only the deceleration rates during bursts that had the same range of swim speeds as the glides $\left(0.8\right.$ to $\left.2.2 \mathrm{~m} \mathrm{~s}^{-1}\right)$, because faster speed causes larger drag. Our statistical model included decelerating rates as a dependent factor, mean speed of decelerating periods and phase (glide/burst) as fixed independent factors, and whale ID as a random factor. Deceleration rates during bursts were substantially larger than those recorded during glides (deceleration during burst: $-0.55 \pm$ $0.51 \mathrm{~m} \mathrm{~s}^{-2}, \mathrm{n}=21$; deceleration during horizontal glide: $-0.026 \pm 0.015 \mathrm{~m} \mathrm{~s}^{-2}, \mathrm{n}=34 ;$ GLMM, $\chi_{1}^{2}=$ 105.7, $\mathrm{p}<0.0001$ ), indicating that deceleration during bursts was not passively attained. Rapid decelerations coincided with larger changes in pitch and heading (GLMM - pitch: $\chi_{1}^{2}=15.8, \mathrm{p}<0.0001$; heading: $\chi_{1}^{2}=25.9, p<0.0001$; swim speed: $\chi_{1}^{2}=65.5, p<$ 0.0001 ). Such changes in heading or pitch are expected during horizontal or vertical turns.

Bursts exhibited a diverse combination of the whale's maneuvers. According to 3D scatter plots of the principal components that were extracted from maximum speed, maximum deceleration, change rate of heading, and rapid and simultaneous changes in body orientation during bursts (Table S1 in the supplement, Fig. 4), the bursts were divided into 2 types: inflectional bursts $(\mathrm{n}=87$ bursts, $82 \%)$ and linear bursts ( $\mathrm{n}=19$ bursts, 18\%). Inflectional bursts had more rapid changes in body orientation and

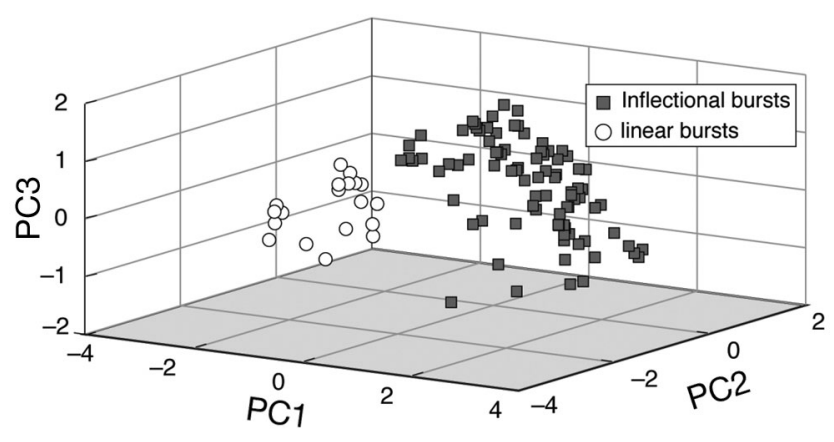

Fig. 4. Physeter macrocephalus. Classification of the bursts into 2 types (inflectional and linear) based on a 3D scatter plot using scores from the first, second, and third principal components (see Table S1 in the supplement at www.intres.com/articles/suppl/m444p289_supp.pdf for details of the components)

more drastic deceleration than linear bursts (Table 3). The details of each type are shown below and in Fig. 5.

There was high variability in (1) changes in swim speed and (2) changes in depth recorded during inflectional bursts. The majority of inflectional bursts could be categorized into 2 different types of changes in swim speed (Table 3): a single acceleration phase or 2 acceleration phases. Changes in depth during inflectional bursts occurred mainly as one of 3 types: descent $(\mathrm{n}=35$ bursts, $40 \%)$, horizontal $(\mathrm{n}=28$ bursts, $32 \%)$, or ascent ( $=17$ bursts, $20 \%$ ). Although inflectional bursts showed similar patterns, including rapid changes in body orientation, drastic deceleration, and turns ( $\mathrm{n}=73$ bursts, $87 \%)$, there were variable combinations of these factors (Table 3 ). 
Table 3. Physeter macrocephalus. Parameters of 2 different burst types of 5 sperm whales. Means $( \pm$ SD) are shown. For details on burst types see section 'Maneuvers and 3D dive profiles during bursts'. Number of bursts with 2 accelerating phases are those with 2 peaks of swimming speed; for example, see Fig. 5a. Accel.: acceleration; decel.: deceleration

\begin{tabular}{|c|c|c|c|c|c|c|c|c|c|c|c|c|}
\hline \multirow[t]{2}{*}{ Burst type } & \multirow[t]{2}{*}{$n$} & \multirow{2}{*}{$\begin{array}{l}\text { Max. } \\
\text { speed } \\
\left(\mathrm{m} \mathrm{s}^{-1}\right)\end{array}$} & \multirow{2}{*}{$\begin{array}{c}\text { Max. } \\
\text { accel. } \\
\left(\mathrm{m} \mathrm{s}^{-2}\right)\end{array}$} & \multirow{2}{*}{$\begin{array}{l}\text { Max. } \\
\text { decel. } \\
\left(\mathrm{m} \mathrm{s}^{-2}\right)\end{array}$} & \multirow{2}{*}{$\begin{array}{l}\text { Swimming } \\
\text { distance } \\
(\mathrm{m})\end{array}$} & \multicolumn{3}{|c|}{$\begin{array}{l}\text { Max. rate of } \\
\text { change }\left({ }^{\circ} \mathrm{s}^{-1}\right)\end{array}$} & \multicolumn{3}{|c|}{$\longrightarrow$ No. of bursts with: } & \multirow{2}{*}{$\begin{array}{c}\text { Gliding just } \\
\text { before } \\
\text { bursts (\%) }\end{array}$} \\
\hline & & & & & & Heading & Roll & Pitch & phase & phases & phases & \\
\hline Inflectional & 87 & $\begin{array}{c}3.6 \\
( \pm 1.0)\end{array}$ & $\begin{array}{c}0.30 \\
( \pm 0.12)\end{array}$ & $\begin{array}{c}0.60 \\
( \pm 0.35)\end{array}$ & $\begin{array}{c}125 \\
( \pm 91)\end{array}$ & $\begin{array}{c}86 \\
( \pm 43)\end{array}$ & $\begin{array}{c}65 \\
( \pm 43)\end{array}$ & $\begin{array}{c}14 \\
( \pm 6)\end{array}$ & 47 & 36 & 4 & 33 \\
\hline Linear & 19 & $\begin{array}{c}3.1 \\
( \pm 0.9)\end{array}$ & $\begin{array}{c}0.25 \\
( \pm 0.12)\end{array}$ & $\begin{array}{c}0.21 \\
( \pm 0.12)\end{array}$ & $\begin{array}{c}128 \\
( \pm 84)\end{array}$ & $\begin{array}{c}25 \\
( \pm 15)\end{array}$ & $\begin{array}{c}15 \\
( \pm 16)\end{array}$ & $\begin{array}{c}7 \\
( \pm 3)\end{array}$ & 18 & 1 & 0 & 63 \\
\hline
\end{tabular}

Linear bursts showed more gradual deceleration rates and slower changes in body angle compared with inflectional bursts (Table 3). Linear bursts did not include any turns. For some linear bursts, no rapid changes in body orientation were recorded $(\mathrm{n}=6$ bursts, $32 \%$ ). Almost all linear bursts had a single acceleration event (Table 3). As with inflectional bursts, depth change during linear bursts occurred in 3 main forms: descent ( $\mathrm{n}=5$ bursts, $26 \%$ ), horizontal $(\mathrm{n}=6$ bursts, $32 \%$ ), and ascent ( $\mathrm{n}=5$ bursts, $26 \%$ ).

\section{DISCUSSION}

Efficient locomotion during breath-hold dives provides the advantage of increased available time at depth for locating and catching prey (Williams et al. 1996). Watwood et al. (2006) concluded that the high diving efficiencies of sperm whales Physeter macrocephalus may be related to efficient locomotion. Deep-diving mammals may conserve oxygen and increase dive durations by employing steady swimming or gliding, when possible, and avoiding energetically costly rapid accelerations. However, all tagged whales in the present study showed short events of highly active swimming at foraging depths, including bursts of speed (Fig. 2). During such bursts, they accelerated rapidly, turned with drastic deceleration, and swam up to $405 \mathrm{~m}$. Here we discuss (1) bursts of speed as part of sperm whale feeding behavior and (2) the hunting process and strategy of sperm whales.

\section{Bursts of speed as part of sperm whale feeding behavior}

Toothed whales employ echolocation clicks to detect their prey and emit buzzes (i.e. a rapid decline in the click interval) to approach prey. Thus, emissions of buzzes have been used as an indicator of feeding events (e.g. Miller et al. 2004b, Watwood et al. 2006, Aguilar Soto et al. 2008, Johnson et al. 2008). By using acoustic tag data, the movements of toothed whales in relation to buzz emissions have previously been investigated. In the case of pilot whales, an increase in vertical speed concurrently with buzz emissions has been shown to reflect prey capture attempts (Aguilar Soto et al. 2008). Sperm whales exhibit buzzes in association with increased changes in body orientation, and such behaviors are thought to indicate final approaches and prey capture (Miller et al. 2004b). Both studies noted that buzz emissions correspond with increasing changes in body orientation or swim speed. Unfortunately, acoustic data were not available in our study. However, our results also showed that $87 \%$ of bursts (i.e. inflectional bursts) included rapid changes in body orientation. Additionally, bursts of speed occurred at depths $>400 \mathrm{~m}$, corresponding with depths where female and immature sperm whales were found to emit buzzes in the Atlantic Ocean, the Gulf of Mexico, and the Ligurian Sea (Watwood et al. 2006). Thus, our results strongly suggest that bursts of speed by the tagged whales recorded in our study are related to feeding events. However, we could not exclude other potential explanations; for example, that the bursts of speed indicate inter- or intra-specific competition. Whales may detect a prey over a wide range and sense another approaching whale. They then may increase their speed to reach the prey before the other whale does. If this behavior occurs, bursts of speed could also be interpreted in relation to feeding events. However, sperm whales probably do not compete against each other. Female sperm whales live in a long-term stable association with each other (Whitehead 2003). Female sperm whales disperse and form a ranked pattern while foraging, thus, possibly avoiding interference by other foraging animals in the same area (Whitehead 2003). Off the Ogasawara Islands, the encounter rate of other deep- 

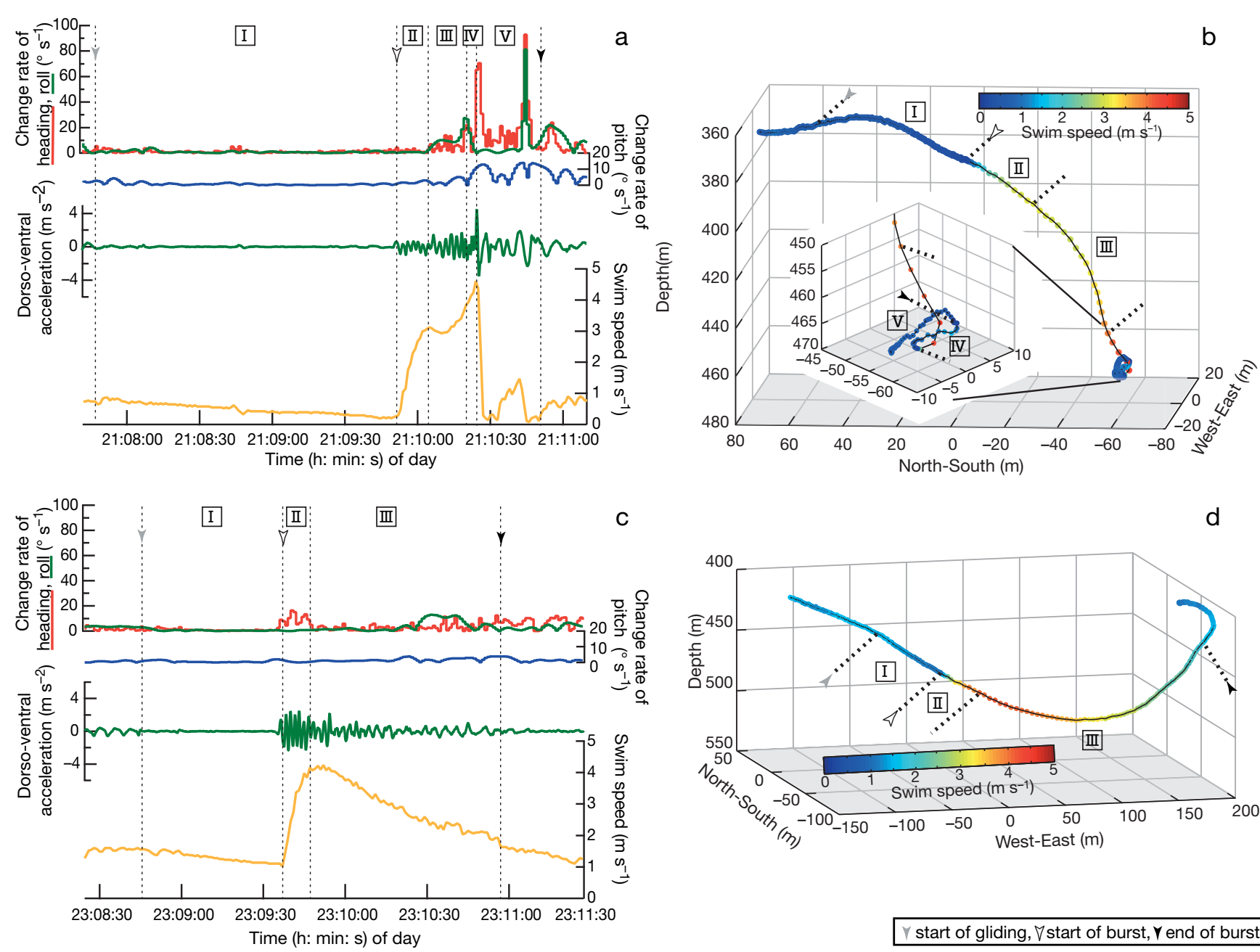

d

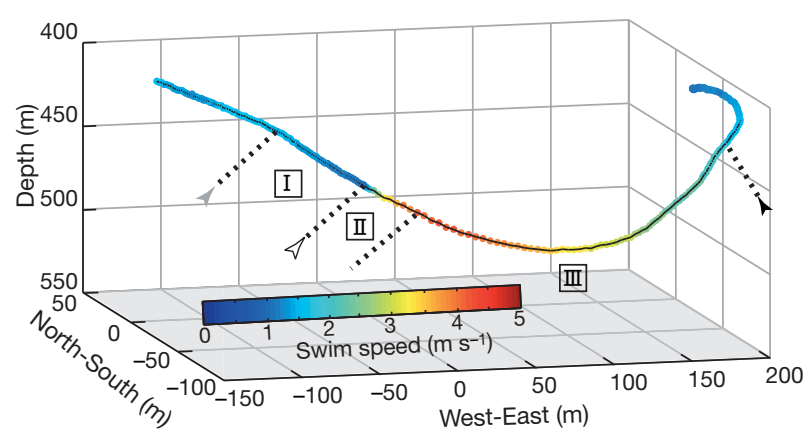

start of gliding, $\nabla$ start of burst, $Y$ end of burst

Fig. 5. Physeter macrocephalus. Typical example of an inflectional and linear burst. Roman numerals show phases of the burst. Each phase of the burst is divided by dashed lines. (a) Time-series diving profiles of an inflectional burst. (b) 3D dive profile of the inflectional burst. The color of dots indicates swim speed. Each dot is shown at $1 \mathrm{~s}$ intervals. Inset illustrates the details of Phases IV and V of the burst. Phase I: gliding was observed in the 117 s preceding the start of the burst. Phase II: rapid acceleration with stroking $\left(0.36 \mathrm{~m} \mathrm{~s}^{-2}\right)$. Phase III: after slight deceleration, the whale again accelerated with stroking $\left(0.26 \mathrm{~m} \mathrm{~s} \mathrm{~s}^{-2}\right)$. Phase IV: the body orientation changed rapidly around the maximum speed; the whale rolled $27^{\circ}$ and then performed a $70^{\circ}$ right turn with a $12^{\circ}$ change in pitch. Phase V: rapid changes in body orientation occurred after drastic deceleration $\left(1.39 \mathrm{~m} \mathrm{~s}^{-2}\right)$ with slow stroking. (c) Time-series diving profiles of a linear burst. (d) 3D dive profile of the linear burst. Phase I: gliding (average speed: $1.3 \mathrm{~m} \mathrm{~s}^{-1}$ ) was observed in the $44 \mathrm{~s}$ preceding the start of the burst. Phase II: acceleration with stroking $\left(0.47 \mathrm{~m} \mathrm{~s} \mathrm{~s}^{-2}\right)$. Phase III: gradual deceleration with slow stroking $\left(0.11 \mathrm{~m} \mathrm{~s}^{-2}\right)$. Rapid changes in body orientation were not observed during this burst. The inflectional burst $(a, b)$ and the linear burst $(c, d)$ were recorded for Whales O8b and O8e, respectively

diving toothed whales (e.g. ziphiid whales) is considerably lower than that of sperm whales (authors' unpubl. data). Therefore, all bursts observed in the present study do not seem to be caused exclusively by inter-specific competition. Another explanation for bursts could be predator avoidance. However, we consider the probability of this explanation to be quite low. This is because killer whales Orcinus orca are the main predators of sperm whales (Whitehead 2003) and usually dive to depths $<200 \mathrm{~m}$ (Baird et al.
2005). However, the majority of bursts in the present study occurred at depths $>400 \mathrm{~m}$. Even if deep-water predators were distributed in our study area, the deceleration behavior observed during the bursts contradicts escape behavior.

Although our results indicate that the bursts of speed are feeding events, sperm whales may not always increase speed to capture their prey. The median number of bursts was 1 per dive (range: 0 to 6 per dive), and $33 \%$ of dives did not include any bursts. 
In contrast, Watwood et al. (2006) reported that the number of creaks (buzzes) in sperm whales averaged 18 per dive in the Atlantic Ocean, the Gulf of Mexico, and the Ligurian Sea. Whitehead (2003) estimated that a female sperm whale consumes, on average, 37 squid per dive, based on stomach content analyses conducted by Clarke (1980). The ratio of bursts to total feeding events is unclear, because we were unable to measure all feeding events. However, the number of bursts is lower than these values. Therefore, prey capture may not always require bursts.

During bursts, tagged whales accelerated with stroking, and usually reached a speed of between 2 and $5 \mathrm{~m} \mathrm{~s}^{-1}$ (Fig. 3b). When a dive included 1 or 4 bursts, the energetic cost of the bursts accounted for 13 and $52 \%$ of the total cost of the dive, respectively (Fig. 2). We roughly estimated the locomotion costs of the burst based on the hydrodynamic drag that the whale experienced (Hind \& Gurney 1997; see 'Locomotion cost' in the supplement for details), and the cost reaches a maximum of $5830 \mathrm{~kJ}$. The mean calorific value is $4.3 \mathrm{~kJ} \mathrm{~g}^{-1}$ in wet weight for muscular squids and $2.3 \mathrm{~kJ} \mathrm{~g}^{-1}$ in wet weight for ammoniacal squids (Clarke et al. 1985). Using these values, we calculated the calories from a small ammoniacal squid weighing $200 \mathrm{~g}$ (cranchids), a muscular squid weighing $8 \mathrm{~kg}$ (ommastrephids), and an ammoniacal squid weighing $24 \mathrm{~kg}$ (architeuthids) to be 460, 34 400, and $55200 \mathrm{~kJ}$, respectively (typical weight of each squid preyed upon by sperm whales according to Whitehead 2003). The caloric value of the squids might be overestimated, because we did not consider digestibility. However, costly bursts should be compensated for by the consumption of relatively nutritious prey, such as large and/or muscular squids, to balance the energy budget. The variable maximum speeds of the bursts (Fig. 3b) suggest that sperm whales can adjust their pursuit speed according to the escape capabilities of their prey, which is most probably related to quality (in size and/or muscular content).

Some large and/or muscular squids were found in the stomach contents of sperm whales off Japan (Kawakami 1980). These squids were observed to be at approximately the diving depths of the whales in our field study, at the same time of year and in the same area. For example, an underwater camera recorded flying squids Ommastrephes bartrami (Lesueur) with muscular mantles between 400 and $800 \mathrm{~m}$ (Kubodera \& Mori 2003), giant squids at $900 \mathrm{~m}$, and Taningia danae from 240 to $940 \mathrm{~m}$ (Kubodera \& Mori 2005, Kubodera et al. 2007). The maximum swim speeds of flying squids and $T$. danae were estimated from video data at $5.3 \mathrm{~m} \mathrm{~s}^{-1}$ (T. Kubodera unpubl. data) and $2.5 \mathrm{~m} \mathrm{~s}^{-1}$ (Kubodera et al. 2007), respectively. As pursuit speeds of predators are predicted to be a function of prey escape speeds (Wilson et al. 2002), the range of maximum speeds of bursts should correspond to the escape speeds of such actively swimming, large and/or muscular squids.

\section{Hunting process and strategy of sperm whales}

For large carnivores the process of hunting usually consists of locating, stalking, chasing, and capturing (Curio 1976). The swimming distances of almost all the bursts were less than about $200 \mathrm{~m}$ (mean: $120 \mathrm{~m}$; Table 3). The maximum detection range of the usual clicks is $325 \mathrm{~m}$ for an individual squid with a mantle length of $25 \mathrm{~cm}$ (Madsen et al. 2007); therefore, the distance of the bursts was shorter than the estimated echolocation detection range. Thus, we infer that the bursts did not begin immediately when the whales detected their prey. During the approaching phases of some carnivores, an advance is made toward the unaware prey until the predator is within attacking range (Curio 1976, Bothma \& le Riche 1989). Such an approach is termed stalking (Curio 1976). Stalking predators avoid noisy body movements that may alert their prey, and their stealthy advance is slow (Curio 1976, MacFarland 1981). Cephalopods are the main prey of sperm whales and are quite sensitive to low-frequency vibrations (Hanlon \& Messenger 1997, Mooney et al. 2010). Furthermore, they respond to local water movements of up to several hundred Hz (Budelmann \& Bleckmann 1988). Although the typical range of echolocation clicks in sperm whales is between 5 and $25 \mathrm{kHz}$ (see Madsen et al. 2002 for details), the squid Loligo pealei, which is heavily preyed upon by toothed whales, does not respond to intense echolocation clicks from squideating toothed whales (Wilson et al. 2007). Thus, cephalopods probably cannot hear echolocation clicks, but detect the water movements caused by predators. Field observations have shown that squids detect and avoid the swimming-generated lowfrequency cues of certain fish predators (Hanlon \& Budelmann 1987). Our results show that gliding (duration: $57 \pm 42 \mathrm{~s}$ ), slow speed $\left(1.2 \pm 0.4 \mathrm{~m} \mathrm{~s}^{-1}\right)$, and inactive body movements were employed before bursts began, suggesting that the whales avoided body movements that might have signaled their presence to the prey. We suspect that the bursts occur within a certain distance during the approach and are sometimes preceded by stalking, which may increase the whale's chances of prey capture (Mac- 
Farland 1981) and reduce the cost of chasing. An alternative explanation for the gliding behavior just prior to bursts is that whales may be selecting a certain prey over other potential prey. Our data, however, are not sufficient to confirm either of these hypotheses. Increasing speed is a costly event; therefore, whales may limit this behavior until they are within target of a specific prey.

Tagged whales swam up to about $405 \mathrm{~m}$ during bursts, suggesting that the whales were chasing fleeing prey. At the end of a successful chase, hunting predators intersect a moving path of their prey to capture it. The prey can escape, even if the speed of the prey $\left(U_{\text {prey }}\right)$ is lower than the speed of the predator $\left(U_{\text {pred }}\right)$, if its turning radius $\left(R_{\text {prey }}\right)$ is smaller than that of the predator (i.e. $U_{\text {pred }}^{2} / R_{\text {pred }}<U_{\text {prey }}{ }^{2} / R_{\text {preyi }}$ Alexander 2003). Therefore, if the prey turns at the last possible moment, the predator cannot intercept the prey even if the predator turns. However, the predator can intercept the prey by turning if turning of the prey occurs too soon (see Fig. 1.2 in Alexander 2003 for details). Thus, predators should adjust their distance to prey and the time of turning. The majority of bursts were inflectional bursts with turning $(87 \%)$, suggesting that sperm whales may make sharp turns to intercept their prey. The remaining $13 \%$ of bursts were linear bursts without turning. For this type, the whales did not need to make sharp turns probably because the prey was not as maneuverable. The two different major types of bursts (inflectional bursts with turning and linear bursts without turning) suggest that sperm whales change their hunting behavior depending on the maneuverability of their prey.

Predator-prey interactions shape the hunting techniques of predators (Curio 1976). Ziphiid whales forage in a similar depth range to sperm whales (Hooker \& Baird 1999, Tyack et al. 2006), and they consume mesopelagic squids (Clarke 1996). Whitehead (2003) suggested that sperm whales have wider feeding niche breadths than the northern bottlenose whale Hyperoodon ampullatus (Forster) and Cuvier's beaked whale Ziphius cavirostris (G. Cuvier), because the ratio of the number of genera to the total number of lower beaks in stomach contents is higher in sperm whales than in the other 2 species. In mammalian carnivores, the ability to hunt a large variety of prey types is influenced by the predator's flexibility in their killing methods (Rowe-Rowe 1978, BenDavid et al. 1991). Therefore, it is likely that sperm whales have a variety of hunting methods to catch a wider variety of prey than other deep-diving species. Our results show that 2 major types of bursts exist, and there are various patterns in $3 \mathrm{D}$ dive profiles, swim speed, and body movement within and between types (Table 3, Fig. 5). Therefore, these results suggest that sperm whales change their hunting behavior according to prey type and prey response, which likely differs by prey type. Teloni et al. (2008) showed that the duration and occurrence of buzzes of male sperm whales varied between foraging depths, suggesting that the whales were foraging on several types of prey with different patterns of mobility. We suspect that sperm whales are capable of using a diverse range of hunting techniques, which makes it possible for them to have wider feeding-niche breadths. The large aerobic capacity of sperm whales allows them to utilize variable hunting methods, including active pursuit, during long-duration dives in order to ensure a broad dietary range.

Acknowledgements. We thank S. Yokoyama (who provided his fishing boat for the research), H. Suda, I. Aizawa, M. Yamasita, S. Nakamura, T. Kaneko and Prof. T. Ura and his team at the University of Tokyo, the staff of SEA TAC and the Ogasawara Whale Watching Association, and the many volunteers who helped with the fieldwork. Members of the International Coastal Research Center, the Ocean Research Institute, the University of Tokyo, the OKAMOTO shipyard, and Little Leonardo helped with the tag design. K. Sato, P. J. O. Miller, R. W. Davis, T. Narazaki, and Y. Watanabe provided us with many helpful suggestions. The present study was supported by the Sasagawa Scientific Research Grant from the Japan Science Society, Grant-in-Aids from the Ministry of Education, Culture, Sports, Science, and Technology, Japan (12NP0201 and 15570012), the program 'Bio-Logging Science of the University of Tokyo (UTBLS)' and the Research Support Expenses from the Ocean Research Institute, The University of Tokyo.

\section{LITERATURE CITED}

Aguilar Soto N, Johnson MP, Madsen PT, Diaz F, Dominguez I, Brito A, Tyack P (2008) Cheetahs of the deep sea: deep foraging sprints in short finned pilot whales off Tenerife (Canary Islands). J Anim Ecol 77: 936-947

Alexander RM (2003) Principles of animal locomotion. Princeton University Press, Princeton, NJ

Amano M, Yoshioka M (2003) Sperm whale diving behavior monitored using a suction-cup-attached TDR tag. Mar Ecol Prog Ser 258:291-295

Aoki K, Amano M, Yoshioka M, Mori K, Tokuda D, Miyazaki N (2007) Diel diving behavior of sperm whales off Japan. Mar Ecol Prog Ser 349:277-287

Baird RW, Hanson MB, Dill LM (2005) Factors influencing the diving behaviour of fish-eating killer whales: sex differences and diel and interannual variation in diving rates. Can J Zool 83:257-267

Beale $\mathrm{T}$ (1839) The natural history of the sperm whale. John van Voorst, London (reprinted in 1973, The Holland Press, London)

Ben-David M, Pellis SM, Pellis VC (1991) Feeding habits and predatory behavior in the marbled polecat (Vormela 
peregusna syriaca). I. Killing methods in relation to prey size and prey behavior. Behaviour 118:127-143

Blackwell SB, Haverl CA, Le Boeuf BJ, Costa DP (1999) A method for calibrating swim-speed recorders. Mar Mamm Sci 15:894-905

Bothma JP, le Riche EAN (1989) Evidence of a flexible hunting technique in Kalahari leopards. S Afr J Wildl Res 19: $57-60$

> Budelmann BU, Bleckmann H (1988) A lateral line analogue in cephalopods: water waves generate microphonic potentials in the epidermal head lines of Sepia and Lolliguncula. J Comp Physiol A 164:1-5

- Clarke A, Clarke MR, Colmes LJ, Waters TD (1985) Calorific values and elemental analysis of eleven species of oceanic squid (Mollusca: Cephalopoda). J Mar Biol Assoc UK 65:983-986

Clarke MR (1970) Function of the spermaceti organ of the sperm whale. Nature 228:873-874

Clarke MR (1980) Cephalopoda in the diet of sperm whales of the Southern Hemisphere and their bearing on sperm whale biology. Disc Rep 37:1-324

> Clarke MR (1996) Cephalopods as prey. III. Cetaceans. Philos Trans R Soc Lond B 351:1053-1065

Clarke MR, Martins HR, Pascoe P (1993) The diet of sperm whales (Physeter macrocephalus Linnaeus 1758) off the Azores. Philos Trans R Soc Lond B 339:67-82

Curio E (1976) The ethology of predation. Springer-Verlag, New York, NY

Davis RW, Fuiman LA, Williams TM, Collier SO and others (1999) Hunting behaviour of a marine mammal beneath the Antarctic fast ice. Science 283:993-996

> Hanlon RT, Budelmann BU (1987) Why cephalopods are probably not 'deaf'. Am Nat 129:312-317

Hanlon RT, Messenger J (1997) Cephalopod behavior. Cambridge University Press, Cambridge

- Hind AT, Gurney WSC (1997) The metabolic cost of swimming in marine homeotherms. J Exp Biol 200:531-542

> Hooker SK, Baird RW (1999) Deep-diving behaviour of the northern bottlenose whale, Hyperoodon ampullatus (Cetacea: Ziphiidae). Proc Biol Sci 266:671-676

Huey RB, Bennett AF (1986) A comparative approach to field and laboratory studies in evolutionary biology. In: Feder ME, Lauder GV (eds) Predator-prey relationships: perspectives and approaches from the study of lower vertebrates. University Chicago Press, Chicago, IL, p 82-98

Johnson MP, Tyack PL (2003) A digital acoustic recording tag for measuring the response of wild marine mammals to sound. IEEE J Oceanic Eng 28:3-12

Johnson M, Hickmoth L, Aguilar Soto N, Madsen PT (2008) Echolocation behaviour adapted to prey in foraging Blainville's beaked whale (Mesoplodon densirostris). Proc Biol Sci 275:133-139

Kawakami T (1980) A review of sperm whale food. Sci Rep Whales Res Inst 32:199-218

Kooyman GL (1989) Diverse divers: physiology and behaviour. Springer-Verlag, Berlin

Kubodera T, Mori K (2003) In situ observations on feeding behavior of neon-flying squid, Ommastrephes bartrami, in the waters off Ogasawara with a compact under-water digital camera. Report of annual meeting on resources and fisheries of squids. Japan Sea National Fisheries Research Institute, Niigata, p 72-77 (in Japanese)

Kubodera T, Mori K (2005) First-ever observations of a live giant squid in the wild. Proc Biol Sci 272:2583-2586
Kubodera T, Koyama Y, Mori K (2007) Observations of wild hunting behavior and bioluminescence of a large deepsea, eight-armed squid, Taningia danae. Proc Biol Sci 274:1029-1034

MacFarland D (1981) The Oxford companion to animal behaviour. Oxford University Press, Oxford

> Madsen P, Wahlberg M, Møhl B (2002) Male sperm whale (Physeter macrocephalus) acoustics in a high-latitude habitat: implications for echolocation and communication. Behav Ecol Sociobiol 53:31-41

Madsen PT, Willson M, Johnson M, Hanlon RT, Bocconcelli A, Aguilar Soto N, Tyack PL (2007) Clicking for calamari: toothed whales can echolocate squid Loligo pealeii. Aquat Biol 1:141-150

> Miller PJO, Johnson MP, Tyack PL, Terray EA (2004a) Swimming gaits, passive drag, and buoyancy of diving sperm whales (Physeter macrocephalus). J Exp Biol 207: 1953-1967

Miller PJO, Johnson MP, Tyack PL (2004b) Sperm whale behavior indicates the use of echolocation click buzzes 'creaks' in prey capture. Proc Biol Sci 271:2239-2247

> Møhl B, Wahlberg M, Madsen PT, Miller LA, Surlykke A (2000) Sperm whale clicks: directionality and source level revisited. J Acoust Soc Am 107:638-648

> Mooney TA, Hanlon RT, Christensen-Dalsgaard J, Madsen PT, Ketten DR, Nachtigall PE (2010) Sound detection by the longfin squid (Loligo pealeii) studied with auditory evoked potentials: sensitivity to low-frequency particle motion and not pressure. J Exp Biol 213:3748-3759

Mori K, Sato F, Yamaguchi M, Suganuma H (1995) Preliminary report of distribution, movement and school structure of the sperm whale in the adjacent waters of the Ogasawara (Bonin) Islands. In: Abstracts of the 11th biennial conference on the biology of marine mammals. Society for Marine Mammalogy, Orlando, FL, p 147

Narazaki T, Shiomi K (2010) Reconstruction of 3-D path (ThreeD_path). Available at: http://bre.soCIkyoto-u.ac. jp/bls/index.php?3D_path

Norris KS, Harvey GW (1972) A theory for the function of the spermaceti organ of the sperm whale (Physeter catodon L.). In: Galler SR, Schmidt-Koenig K, Jacobs GJ, Belleville RE (eds) Animal orientation and navigation. NASA Special Publications, Washington, DC, p 397-417

Otani S, Naito Y, Kato A, Kawamura A (2001) Oxygen consumption and swim speed of the harbor porpoise Phocoena phocoena. Fish Sci 67:894-898

Rowe-Rowe DT (1978) Comparative prey capture and food studies of South African mustelines. Mammalia 42: 175-196

Sakai M, Aoki K, Sato K, Amano M and others (2011) Swim speed and acceleration measurements of short-finned pilot whales (Globicephala macrorhynchus) in Hawai'i. Mamm Study 36:55-59

Sato K, Mitani Y, Cameron MF, Siniff DB, Naito Y (2003) Factors affecting stroking patterns and body angle in diving Weddell seals under natural conditions. J Exp Biol 206:1461-1470

Secor SM (1995) Ecological aspects of foraging mode for the snakes Crotalus cerastes and Masticophis flagellum. Herpetol Monogr 9:169-186

> Shiomi K, Narazaki T, Sato K, Shimatani K, Arai N, Ponganis PJ, Miyazaki N (2010) Data-processing artefacts in three-dimensional dive path reconstruction from geomagnetic and acceleration data. Aquat Biol 8:299-304

Teloni V, Johnson MP, Miller PJO, Madsen PT (2008) Shal- 
low food for deep divers: dynamic foraging behavior of male sperm whales in a high latitude habitat. J Exp Mar Biol Ecol 354:119-131

Tyack PL, Johnson M, Aguilar Soto N, Sturlese A, Madsen PT (2006) Extreme diving of beaked whales. J Exp Biol 209:4238-4253

Vogel S (1981) Life in moving fluids. The physical biology of flow. Willard Grant Press, Boston, MA

Watanabe Y, Baranov EA, Sato K, Naito Y, Miyazaki N (2004) Foraging tactics of Baikal seals differ between day and night. Mar Ecol Prog Ser 279:283-289

Watanabe Y, Baranov EA, Sato K, Naito Y, Miyazaki N (2006) Body density affects stroke patterns in Baikal seals. J Exp Biol 209:3269-3280

> Watkins WA, Daher MA, Dimarzio NA, Samuels A and others (2002) Sperm whale dives tracked by radio tag telemetry. Mar Mamm Sci 18:55-68

Watwood SL, Miller PJO, Johnson M, Madsen PT, Tyack PL (2006) Deep-diving foraging behavior of sperm whales

Editorial responsibility: Rory Wilson,

Swansea, UK
(Physeter macrocephalus). J Anim Ecol 75:814-825

Whitehead H (2003) Sperm whales: social evolution in the ocean. University of Chicago Press, Chicago, IL

Williams T, Shippee S, Rothe M (1996) Strategies for reducing foraging costs in dolphins. In: Greenstreet S, Tasker $M$ (eds) Aquatic predators and their prey. Fishing News Books, University Press, Cambridge, p 4-9

Wilson M, Hanlon RT, Tyack PL, Madsen PT (2007) Intense ultrasonic clicks from echolocating toothed whales do not elicit anti-predator responses or debilitate the squid Loligo pealeii. Biol Lett 3:225-227

Wilson RP, Wilson MP, Link R, Mempel H, Adams NJ (1991) Determination of movements of African penguins Spheniscus demersus using a compass system: dead reckoning may be an alternative to telemetry. J Exp Biol 157:557-564

> Wilson RP, Ropert-Coudert Y, Kato A (2002) Rush and grab strategies in foraging marine endotherms: the case for haste in penguins. Anim Behav 63:85-95

Submitted: January 14, 2011; Accepted: August 26, 2011 Proofs received from author(s): December 19, 2011 